\title{
Análise das relações entre as paisagens construídas e representações sociais dos municípios de São José dos Campos e Arapeí
}

\author{
Analysis of the relations between the built landscapes and social \\ representations of the municipalities of São José dos Campos and Arapeí
}

Daniel José de Andrade, Adriane Aparecida Moreira de Souza, Cilene Gomes, Valéria Zanetti

Universidade do Vale do Paraíba (UNIVAP), São José dos Campos, SP, Brasil

\section{Resumo}

A Região Metropolitana do Vale do Paraíba e Litoral Norte (RMVPLN) configura-se como cenário riquíssimo para estudos sobre as representações sociais. A atual conformação territorial revela a ocorrência de processos históricos peculiares a cada municipalidade dessa região e, portanto, é notável a heterogeneidade em seu conteúdo socioespacial. 0 estudo das representações sociais tem possibilitado a interpretação das realidades regionais por meio da leitura do espaço construído e de seus símbolos. Para este estudo foram selecionados os municípios de São José dos Campos e Arapeí, nos quais os contrastes socioespaciais são representativos da diversidade regional e cujas identidades locais são bastante singulares. Tais municípios foram analisados sob a perspectiva da representação social considerando as simbologias que consolidaram as identidades criadas e ressignificadas ao longo do século XX. Nesse sentido, este artigo tem como objetivo analisar São José dos Campos e Arapeí considerando as paisagens construídas e as representações sociais propagadas pelos respectivos poderes públicos locais.

Palavras-chave: Planejamento urbano. Representações sociais. Espaço urbano. Identidade local.

\section{Abstract}

The Metropolitan Region of the Paraíba Valley and North Coast (MRPVNC) represents a fruitful scenario the study of social representations. The current territorial conformation exposes the occurrence of historical processes peculiar to each municipality in this Region, and therefore, the remarkable heterogeneity in its socio-spatial

DJA é doutorando em Planejamento Urbano e Regional pela Universidade do Vale do Paraíba (UNIVAP), graduado em Geografia na UNIVAP, mestre em Planejamento Urbano e Regional na UNIVAP, e-mail: joseandrade26@yahoo.com.br

AAMS é docente do Programa de Pós-graduação em Planejamento Urbano e Regional da UNIVAP, doutora em Geografia pela Faculdade de Filosofia, Letras e Ciências Humanas da Universidade de São Paulo (FFLCHUSP), mestre em Planejamento Urbano e Regional na UNIVAP, graduada em Geografia na UNIVAP, e-mail: adriane@univap.br

CG é docente pesquisadora do Programa de Pós-graduação em Planejamento Urbano e Regional da UNIVAP, doutora em Geografia Humana pela FFLCHUSP, mestre em Geografia Humana na FFLCHUSP, graduada em Arquitetura e Urbanismo pela Faculdade de Arquitetura e Urbanismo da USP, e-mail: cilenegomes2011@gmail.com

VZ é docente do Programa de Pós-graduação em Planejamento Urbano e Regional da UNIVAP, doutora em História na Pontifícia Universidade Católica de São Paulo, mestre em História na Pontifícia Universidade Católica do Rio Grande do Sul, graduada em História na Universidade Federal de Ouro Preto, e-mail: vzanetti@univap.br 
content. The study of social representations has allowed the interpretation of regional realities by means of the reading of the built space and its symbols. The municipalities of Sao José dos Campos and Arapeí, whose socio-spatial contrasts are representative of the regional diversity and which have local identities that are quite unique, were selected for the present study. These municipalities were analyzed from the perspective of social representations, considering the symbologies that have consolidated the identities created and resignified over the twentieth century. In this sense, this article presents the analysis of São José dos Campos and Arapeí considering the built landscapes and the social representations propagated by their respective local authorities.

Keywords: Urban planning. Social representations. Urban space. Local identity.

\section{Introdução}

Os estudos sobre representações sociais difundiram-se, desde a década de 1960, a partir da Psicologia Social para diversas disciplinas do conhecimento. Entendendo as representações sociais enquanto saberes que uma sociedade elabora sobre si, que os diferentes grupos sociais constroem sobre suas experiências em dado contexto sociocultural, esses estudos tornam-se em nossos dias de grande importância no campo do planejamento urbano e regional.

Dado que as representações sociais são fundadas nas práticas sociais inerentes à incessante reorganização da vida social - mediante a ação de sujeitos sociais agindo no espaço de vida em comum (espaço público) - e nos processos de comunicação que a sustenta, constituem a dimensão da significação desse espaço de vida.

Em razão de ser a esfera pública o espaço da ação, do discurso e da diversidade de perspectivas dos sujeitos sociais em relação às preocupações comuns com o espaço de vida em comum e aos projetos para o futuro, as representações sociais estão, hoje, no centro do debate sobre as experiências de participação social e cidadania em diferentes regiões e cidades nas quais se elabora a reconstrução coletiva do sentido do lugar social e, por conseguinte, do lugar ele próprio, com seus potenciais de transformação.

No intuito de uma apropriação dos aportes teóricos das representações sociais, a presente discussão propõe-se compreender as relações entre paisagens construídas e representações sociais do espaço urbano de São José dos Campos e Arapeí (Figura 1), enquanto mediações para um cotejamento dos modelos de desenvolvimento urbano-regional implementados por esses dois municípios paulistas no contexto histórico de remodelação da Região Metropolitana do Vale do Paraíba e Litoral Norte (RMVPLN).

0 exercício de análise e a discussão proposta trazem uma compreensão do processo de transformações do espaço urbano dos dois municípios e de algumas representações sociais legitimadas socialmente ou veiculadas (observadas) no site das respectivas prefeituras, indicando que as significações do lugar variam igualmente de acordo com distintos períodos da história. Constata-se ainda que, em cada período, as paisagens urbanas e as simbologias se tornam representativas dos interesses de diversos agentes que atuam nos territórios em questão.

A metodologia adotada incluiu a construção de um referencial teórico acerca das representações sociais em sua relação com o espaço construído da cidade e o levantamento iconográfico e documental, compreendendo consultas a revistas, jornais, reportagens, legislação municipal e, ainda, a páginas eletrônicas de instituições como o Instituto Brasileiro de Geografia e Estatística (IBGE), o Instituto de Geografia e Cartografia (IGC), a Fundação Sistema Estadual de Dados (SEADE) e ao Atlas do Desenvolvimento Humano no Brasil de 2013.

Embora a história mostre que ao longo do tempo tais municípios vivenciaram contextos sociais, econômicos e políticos distintos, na atualidade, os dois municípios caminham para um novo rumo de desenvolvimento e, assim, para a construção de uma nova identidade socioespacial. Esse é o caso de Arapeí, município que tem uma história econômica vinculada ao período áureo e de declínio da produção cafeeira e, na atualidade, mostra sinais de fortalecimento das atividades do setor de turismo. E, de igual modo, de São José dos Campos, que rompeu com as representações sociais de cidade sanatorial para se consolidar como cidade-tecnológica e "capital" regional do Vale do Paraíba Paulista. 


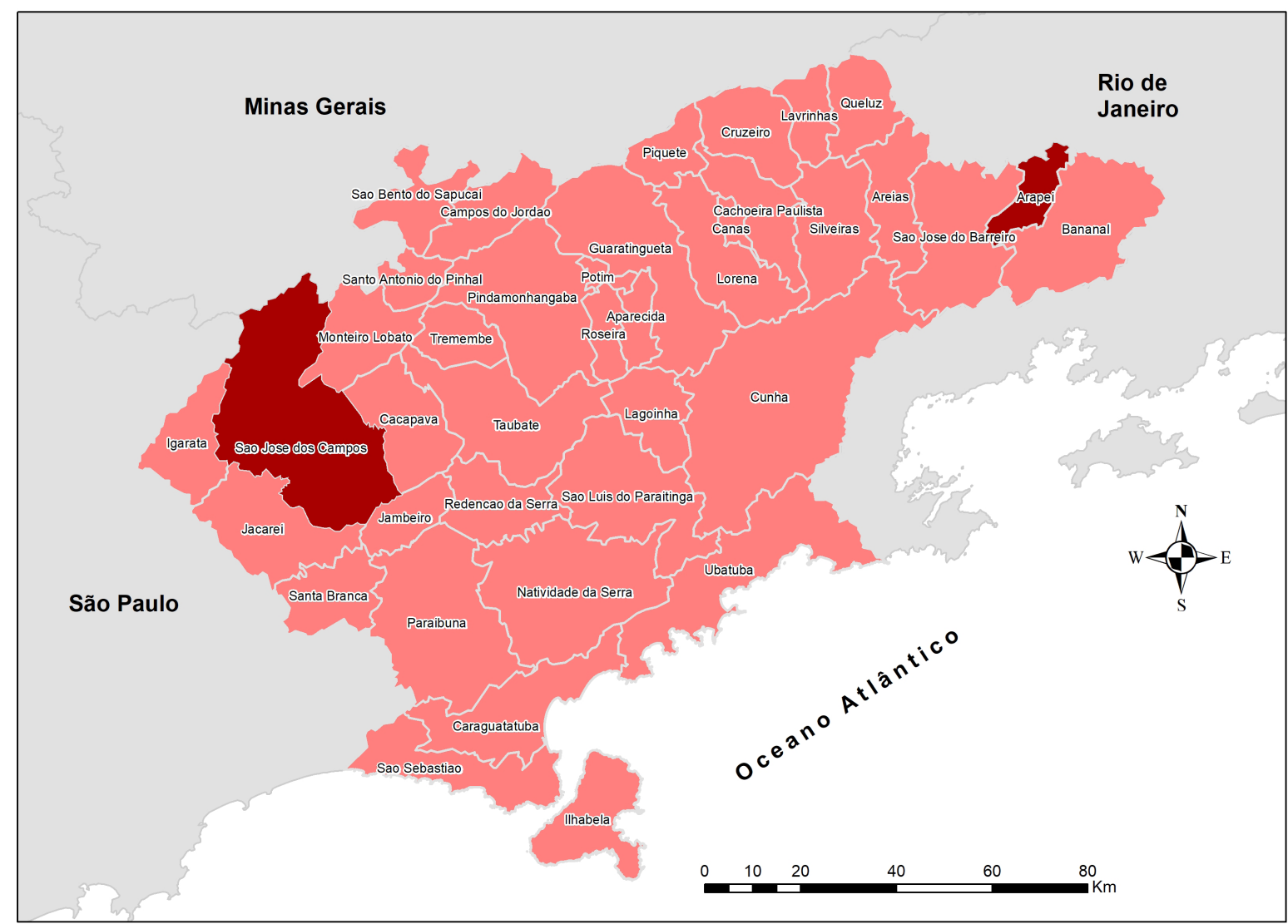

Figura 1 - Localização dos municípios de São José dos Campos e Arapeí na RMVPLN Fonte: IBGE (2010). Elaborado por Daniel José de Andrade.

\section{Representações sociais: ferramenta para o estudo da produção e das significações do espaço urbano}

O estudo das representações sociais teve início na segunda década do século XX, no campo da Psicologia Social, por meio da abordagem pioneira de Serge Moscovici. Atribui-se a Durkheim, ao estudar sobre "ideação coletiva", as primeiras referências à noção de representações sociais enquanto "produções mentais sociais". Moscovici, considerado o precursor dessa abordagem, tentou dar especificidade ao fenômeno das representações nas sociedades contemporâneas, caracterizadas pela fluidez das trocas e das comunicações, pelo desenvolvimento da ciência e pela mobilidade social.

Para Moscovici, as representações sociais são formas de conhecimento social, saberes que uma sociedade desenvolve e sustenta sobre si própria, mediante a ação de sujeitos sociais agindo em um espaço comum a todos, onde uns se encontram com outros (Jovchelovitch, 1994). 0 espaço público seria, assim, o terreno sobre o qual as representações sociais podem se desenvolver e, por isso, tais construções simbólicas, radicadas no tecido social e cultural, são indissociáveis do espaço de todos, histórica e socialmente construído, em permanente transformação.

Sentidos são atribuídos aos eventos da vida social urbana pelos diversos sujeitos sociais a partir de interações cotidianas, de natureza comunicacional, estabelecidas entre si. Esses sentidos constituem uma forma de conhecimento fundado nas práticas sociais (Sêga, 2000; Jovchelovitch, 1994), no senso comum (Jodelet, 2001), na opinião pública, em uma tradução ou versão da realidade (Arruda, 2002, p. 11).

Jodelet (2002) também ressalta a prevalência do ser social na construção do espaço de vida em comum. Segundo a autora (2002, p. 35) o espaço "[...] representa uma ordem social e, por esse motivo, presta-se ao jogo das interpretações, que pode ser 
analisado por meio das representações construídas pelos sujeitos sociais".

Assim como Jovchelovitch (1994) ressalta a estreita relação entre o mundo material e o mundo simbólico, situando o caráter mediador das representações sociais, Jodelet (2002) também as posiciona no campo da dinâmica relacional entre a materialidade dos lugares, a aparência física de uma cidade, por exemplo, e os elementos humanos inscritos no ambiente da vida social, onde se originam e se modulam as especificidades dos estilos de vida e as identidades locais.

As representações sociais nasceriam e se desenvolveriam no espaço relacional entre as dinâmicas da atividade social e as paisagens construídas. Daí o interesse no conceito de espaço potencial de Winnicott, apropriado por Jovchelovitch (1994), na equiparação com o espaço dos símbolos, da atividade simbólica.

Entendendo o espaço potencial como um estado intermediário no qual o sujeito (inscrito socialmente) reconhece e elabora mentalmente a realidade, o mundo e seu lugar no mundo, subentende-se a coexistência, no espaço potencial, da realidade e da simbolização. A garantia da atividade simbólica estaria na referência ao mundo e sua essência estaria na capacidade de os sujeitos, em progressivo desenvolvimento, se reconhecerem e elaborarem a realidade compartilhada.

As representações sociais constituem o "[...] espaço potencial de fabricação comum, onde cada sujeito vai além de sua própria individualidade para entrar num domínio diferente, o domínio da vida em comum" (Jovchelovitch, 1994, p. 81), no qual são explorados os significados que a vida social assume na dimensão pública.

Para compreender que o espaço potencial é o espaço dos símbolos, Jovchelovitch (1994, p. 74) esclarece:

Símbolos pressupõem a capacidade de evocar a presença apesar da ausência, já que sua característica fundamental é que eles significam uma outra coisa. Nesse sentido, eles criam o objeto representado, construindo uma nova realidade para a realidade que já está lá. [...] Através dos símbolos, coisas diferentes podem significar umas às outras e podem mergulhar umas nas outras; eles permitem uma variabilidade infinita, e ainda assim, são referenciais.

Jovchelovitch (1994) reforça, a respeito da definição de Moscovici, que as representações sociais são conhecimentos da realidade com dois lados interligados: um lado figurativo, imageante (criador de imagens), e o lado simbólico propriamente dito. Na constituição de imagens que são ideias e de ideias que são imagens, o conhecimento da realidade é concebido pelos sujeitos sociais de forma direta (nas ruas, nas praças, nos rituais coletivos) ou mediado institucionalmente, assumindo suas formas de representação.

O estudo do espaço urbano de Paris, realizado por Milgram \& Jodelet (1976), constatou que "[...] as representações do espaço são também Representações Sociais". Para Jodelet (2002, p. 35), o referido estudo serviu de parâmetro para o "[...] estudo da produção e das significações do espaço urbano em termos de representação socioespacial".

No Brasil, Ângela Arruda inspirou-se nos estudos de Jodelet e Milgram propondo o uso de mapas mentais, expressos pelo desenho de cartografias, enquanto ferramenta metodológica para discutir a dimensão do imaginário na construção das representações sociais, analisando as perspectivas do imaginário coletivo de jovens estudantes na representação social da nação brasileira. Com o propósito de incentivar a expressão desenhada dos mapas mentais, entende-se que o lado imageante das representações sociais nada mais é do que um modelo figurativo da estrutura conceitual, priorizado neste estudo.

A constatação feita por Cruz \& Arruda (2008) de que a representação da cidade é uma representação social que também estrutura o espaço urbano é de extrema relevância para os estudos urbanos e regionais e, particularmente, para o planejamento urbano e regional. Sobretudo porque nenhum espaço se reconstrói sem que antes esse espaço e essa reconstrução tenham sido concebidos mentalmente, enquanto representação social, saberes sociais enfim transformados em ação.

Segundo Jovchelovitch (1994), ainda que o mundo seja o solo comum a todos, as posições dentro dele variam e nunca podem coincidir plenamente. Daí a importância das análises em vista de representações sociais construídas coletivamente por diferentes grupos sociais. Segmentos diversos das diferentes instâncias da vida social (político-institucional, cultural-ideológica, econômico-produtiva) da população habitante de um lugar qualquer podem conceber representações sociais distintas e, por isso, podem e devem configurar recortes para estudos e análises também passíveis de seres conduzidos de modo distinto.

Os aportes das representações sociais nos convidam a ir além do estudo da sociedade, do espaço e da história como meras abstrações, recuperando a sua conexão 
com a dimensão dos sujeitos sociais portadores dessa história e responsáveis pela transformação da sociedade e a remodelação de seu espaço de vida em comum (Jovchelovitch, 1994).

Como também instiga essa mesma autora, num mundo em que "[...] estamos atravessados pela violência concreta de relações sociais desiguais", mas também "pela força da palavra" alcançando populações cada vez mais numerosas, as representações sociais se tornam, elas próprias, mediações no processo de construção coletiva do sentido do mundo, da nação, do lugar em que se vive, consolidando formas de resistência, participação e exercício da cidadania.

\section{São José dos Campos, do passado recente à história do presente em seus aspectos econômicos, sociais e urbanos}

A fase sanatorial do município de São José dos Campos, demarcada de 1935 a 1945, representou o período da estância climatérica para o tratamento da tuberculose. Segundo Rosemberg (1999, p. 20), o município possuía, em 1930,

[...] 8.000 habitantes autóctones e albergava cerca de 2.000 tuberculosos, distribuídos em quatro sanatórios (três beneficentes com doentes pagantes e indigentes e um particular de propriedade de um médico), além de dezenas de pensões e muitas 'repúblicas' de tuberculosos.

Na condição de estância para o tratamento da doença, Vianna (2010, p. 67) relata que

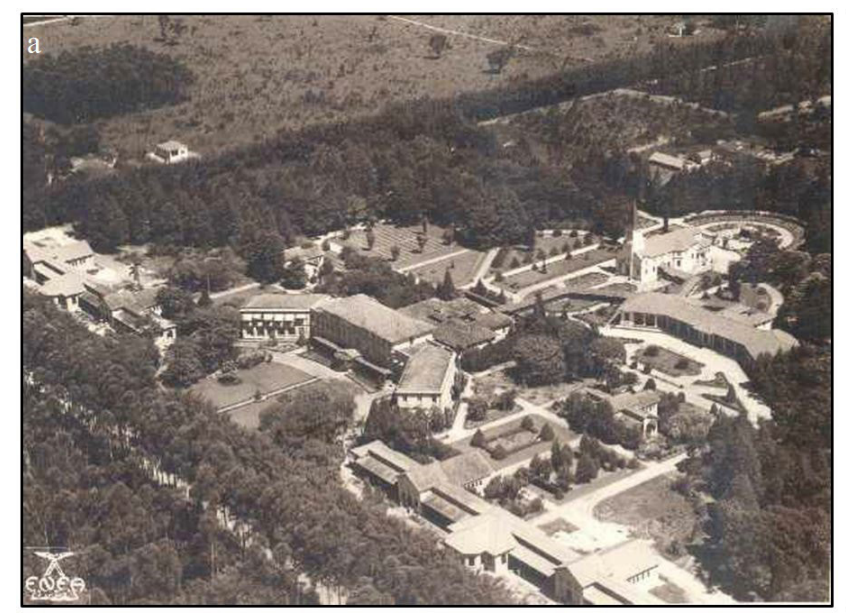

[...] a cidade se urbanizou e expandiu demograficamente, neste período, no ritmo nacional, possibilitada pela condição climática. [...] E a sociedade especificada neste conjunto histórico - a cidade sanatorial - organizou o território de modo a demarcar as diferenças, a localizar as funções, mas também imprimir os desejos e a possibilitar movimentos de transição.

No período de cidade-estância, o município teve na doença o objeto de sua representação social. Porém essa representação foi, na década de 1950, gradativamente transformada. Segundo Vianna (2010, p. 61),

[...] os constantes incrementos na população empregada na indústria, com ampliação também dos setores de comércio, de serviços e das atividades sociais refletem os processos gradativos de urbanização e industrialização. O perfil da população tuberculosa refletiu esta mudança: a doença se fez representar na nova população economicamente ativa e particularmente suscetível - em especial, os tecelões empregados do principal ramo industrial da cidade.

Fotos aéreas obtidas nos anos de 1939 e 1940 pelo Instituto de Geografia e Cartografia (IGC) revelam a configuração urbana (b) da região central, bem como o Sanatório Vicentina Aranha (a) no município de São José dos Campos (Figura 2).

A representação da cidade pela doença foi gradativamente transformada a partir da década de 1950, juntamente com a transformação da paisagem construída, que se deu pelos elementos modernos

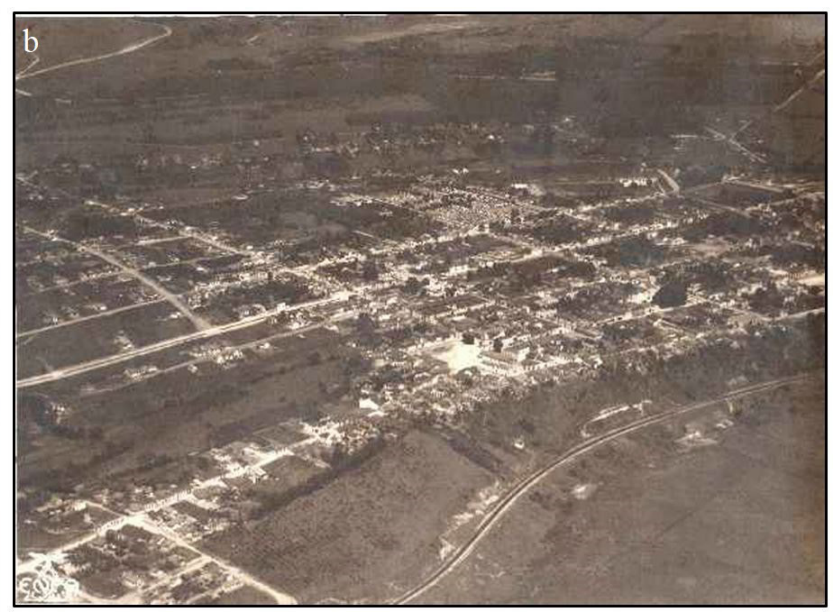

Figura 2 - Sanatório Vicentina Aranha (a) e núcleo urbano de São José dos Campos, 1939/1940 (b) Fonte: IGC (2015). 
de produção do espaço. Entre eles, a indústria e a tecnologia, que se tornaram os principais marcos da nova representação social do município de São José dos Campos. Segundo dados investigados por Müller (1969), a partir da década de 1940, a população urbana superou a população rural. Nas décadas posteriores, o número de pessoas residindo na área urbana do município duplica e triplica em relação à população rural (Tabela 1).

Mas a década de 1950 foi o verdadeiro divisor de águas para as transformações que culminaram na configuração atual da paisagem do município de São José dos Campos. Nessa década ocorreu a instalação de infraestruturas militares, como o Instituto Tecnológico de Aeronáutica (ITA), finalizado em 1951, e o Instituto do Centro Técnico de Aeronáutica (CTA), em 1953. Nessa mesma década, políticas públicas do projeto nacional desenvolvimentista contemplaram a Região do Vale do Paraíba com a construção da Rodovia Presidente Dutra, em substituição à antiga Estrada Rio-São Paulo. De acordo com Souza \& Costa (2010, p. 100),

[...] a inauguração da primeira pista da rodovia Presidente Dutra, em 1950, e sua duplicação, em 1968, implicou maior facilidade de escoamento de mercadorias e o acesso a matérias-primas utilizadas pelas indústrias, atraindo novas instalações e contribuindo para a diversificação da produção industrial, que passa a ocorrer, por empresas do setor de telecomunicação, químico, farmacêutico e automobilístico.

Na Figura 3 são apresentadas duas amostras dos novos complexos industriais-tecnológicos que foram instalados na cidade na década de 1950, a exemplo da indústria farmacêutica, representada pela Johnson \& Johnson (a), instalada em 1953, e do Centro Tecnológico da Aeronáutica (b), instalado nesse mesmo ano. Nesse último complexo, os traços da arquitetura moderna estão presentes pelos projetos de Oscar Niemeyer.

Com os primeiros passos da modernidade dados pela arquitetura industrial, o município de São José dos Campos, a partir da segunda metade do século XX, passou por períodos gradativos de industrialização. A partir da década de 1960, devido à localização do município, próximo à capital paulista, São José dos Campos, em sua terceira fase do processo de industrialização, torna-se, juntamente com os municípios de Campinas e Sorocaba, palco do processo de descentralização industrial da metrópole paulista, que se estende ao
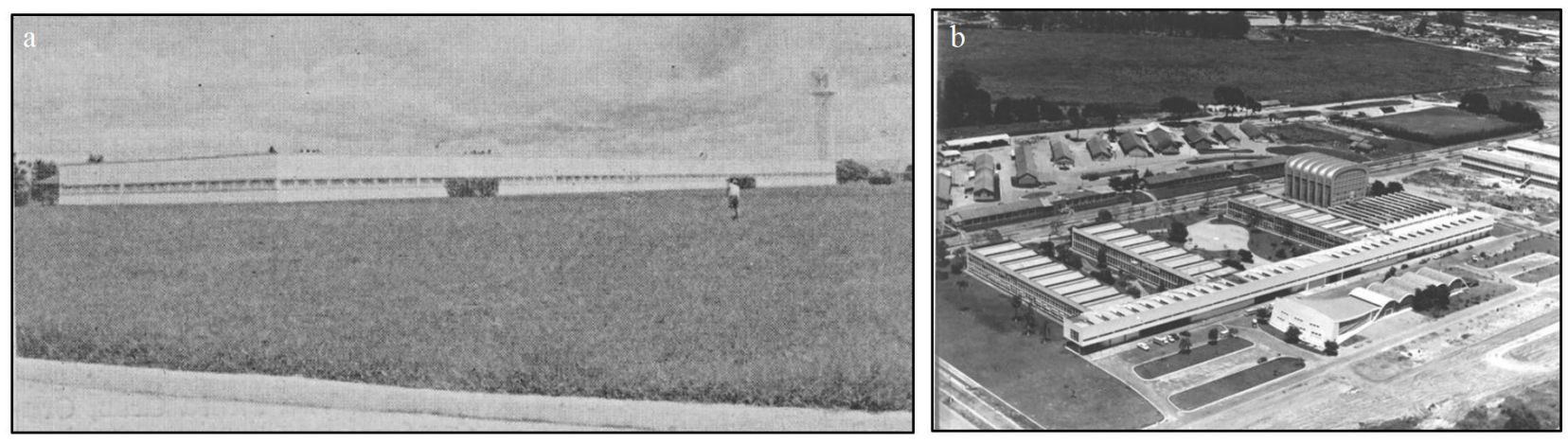

Figura 3 - Fábrica da Johnson \& Johnson, s/d* (a) e complexo militar CTA, s/d** (b) Fonte: Müller (1969)*; FAB (2012) ${ }^{\star \star}$.

Tabela 1 - Dados demográficos de São José dos Campos entre 1934 e 1960

\begin{tabular}{ccccccc}
\hline Ano & Total & $\%$ & Urbana & $\%$ & Rural & $\%$ \\
\hline $\mathbf{1 9 3 4}$ & 28.841 & 100 & 8.659 & 30,02 & 20.182 & $69,98 \%$ \\
$\mathbf{1 9 4 0}$ & 24.446 & 100 & 13.491 & 44,81 & 10.955 & $55,19 \%$ \\
1950 & 38.520 & 100 & 25.892 & 67,22 & 12.628 & $32,78 \%$ \\
1960 & 70.554 & 100 & 55.349 & 78,45 & 15.205 & $21,55 \%$ \\
\hline
\end{tabular}

Fonte: Müller (1969). 
Tabela 2 - Dados demográficos de São José dos Campos - 1934 e 2010

\begin{tabular}{ccccccc}
\hline Ano & Total & $\%$ & Urbana & $\%$ & Rural & $\%$ \\
\hline $1934^{\star}$ & 28.841 & 100 & 8.659 & 30,02 & 20.182 & 69,98 \\
$2010^{\star \star}$ & 629.921 & 100 & 617.106 & 97,97 & 12.815 & 2,03 \\
\hline
\end{tabular}

Fonte: *Müler (1969); ${ }^{* \star \mid B G E ~(2010) . ~}$

interior por uma área de 100 quilômetros de raio. Tais municípios tornam-se os "[...] novos núcleos de agregação industrial do Estado" (Costa, 1982, apud Souza, 2008, p. 35).

Em meio ao processo intenso de industrialização e urbanização, o segmento tecnológico estrategicamente planejado pela ação do Estado brasileiro, desde 1950, ganhou força com o Plano Nacional de Desenvolvimento I e II, sobretudo na década de 1970. Para Becker \& Egler (2003, p. 133), foi com uma política de apropriação tecnológica contida no II Plano Nacional de Desenvolvimento (1975-1979) que se efetivaram os esforços e recursos em ciência e tecnologia. Esses,

[...] foram parcialmente veiculados para centros de Pesquisa e Desenvolvimento (P\&D) estatais e militares, que assumiram uma posição central na estrutura do desenvolvimento científico-tecnológico brasileiro.

Becker \& Egler (2003, p. 134) ressaltam que “[...] o locus do projeto geopolítico moderno é o Vale do Paraíba do Sul [...] onde o objetivo de construir um complexo militar-industrial fica em evidência".

Nesse contexto e referindo-se a São José dos Campos, Souza (2008, p. 165) esclarece que

[...] cabe considerar mais uma vez o papel do conhecimento e da pesquisa científica na sustentação do desenvolvimento do setor aeroespacial e na consolidação do município de São José dos Campos em um polo científico-tecnológico.

Na composição do polo científico-tecnológico, a inserção de indústrias de base tecnológica, a exemplo da criação da Empresa Brasileira de Aeronáutica (EMBRAER), juntamente com a instalação de Instituições de Ensino e Pesquisa como o Instituto Tecnológico de Aeronáutica (ITA) e o Instituto Nacional de Pesquisas Espaciais (INPE) garantiram a consolidação do município como centro da tecnologia aeroespacial no país.
A constituição da cidade da tecnologia contribuiu para a implantação de infraestrutura urbano-regional, bem como atraiu investimentos e um contingente populacional para o município e para a região. Dados demográficos de 2010 não lembram em nada os da fase sanatorial do século passado. Nesse ano, conforme o IBGE, São José dos Campos possuía uma população total de 629.921 habitantes, sendo 97,97\% residentes em área urbana - só 2,03\% viviam em área considerada rural, diferentemente do ano de 1934, na fase senatorial, quando aproximadamente $70 \%$ da população residia no campo (Tabela 2).

As alterações ocorridas no período entre 1950 e 2010 não se deram somente na infraestrutura instalada no município de São José dos Campos, a arquitetura urbana do município também foi transformada e ressignificada no decorrer dessas décadas. A exemplo do trecho da Avenida Florestan Fernandes (a) e do espaço urbano central do município de São José dos Campos (b) (Figura 4).

Nas décadas iniciais do século XXI, o meio geográfico natural tornou-se mais escasso, parecendo não fazer parte da dinâmica da área urbana, a não ser pela presença dos poucos parques ou áreas verdes, que agem como pequenos "pulmões ecológicos" em meio ao emaranhado de asfalto e concreto. A nova forma conurbada da paisagem urbana, com municípios como os de Jacareí e de Caçapava, criou uma tipologia para São José dos Campos que a aproxima de uma grande aglomeração urbana globalizada. Aliado a isso, os fluxos materiais e imateriais que se realizam no interior dessa municipalidade, bem como a base produtiva alicerçada sobre a indústria e tecnologia, trazem uma expressão fidedigna de um meio geográfico com características técnico-científico-informacional ${ }^{1}$.

\footnotetext{
${ }^{1}$ Ver discussão realizada por Andrade (2015) em dissertação de mestrado intitulada Desenvolvimento regional e o meio técnico-científico-informacional: Uma análise dos contrastes socioeconômicos e espaciais da Região Metropolitana do Vale do Paraíba e Litoral Norte.
} 


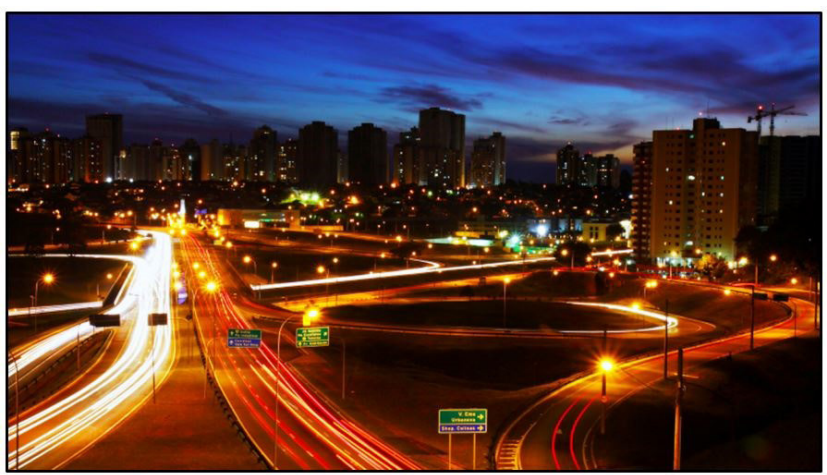

a

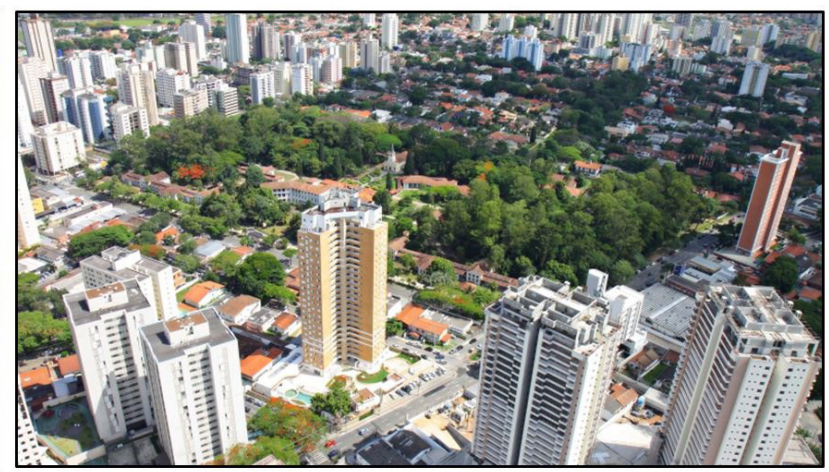

b

Figura 4 - Avenida Florestan Fernandes (a) e espaço urbano central do município de São José dos Campos (b) Fonte: PMSJC (São José dos Campos, 2015).

Nessa municipalidade, novos modelos de uso e ocupação do solo se constituíram, permeados pelos loteamentos e arranha-céus que impactariam até o flâneur, descrito por Rouanet (1992, apud Freitag, 2012) como o "[...] viajante moderno que passeia pela cidade" de Paris do século XIX. Assim como o flâneur do século passado, um rápido passeio pelo município de São José dos Campos, lançando o olhar sobre as diversas realidades existentes, revela sensações distintas.

Com a vocação para a pesquisa e a tecnologia, a cidade atravessada pela Rodovia Presidente Dutra revela também o território dos automóveis, seguidos de locais altamente valorizados por loteamentos privados, finalizando com a cidade dominada pelo setor de comércio e serviços. Nota-se também a existência de uma área de ocupação dispersa, formada por bairros, dada pelo zoneamento urbano adotado a partir da década de 1970, que contribuiu para uma paisagem dicotômica no município. E nesse fracionamento territorial estão presentes bairros periféricos, muitos deles isolados geograficamente, ficando então a pergunta: o conjunto social participa realmente dos benefícios dessa municipalidade moderna?

Para tal questionamento, a consulta a dados secundários sobre a condição de vida dos munícipes de São José dos Campos para o ano de 2010 revelou que grande parte da população do município apresenta um Índice de Desenvolvimento Humano (IDH) que varia entre o médio índice 0,63 até o mais alto indicador 0,95 , bem próximo a 1 . Ou seja, mesmo com a representação do município voltada ao que há de mais moderno, grande parte da população, em especial a residente em áreas periféricas, compartilha do IDH médio (Figura 5).

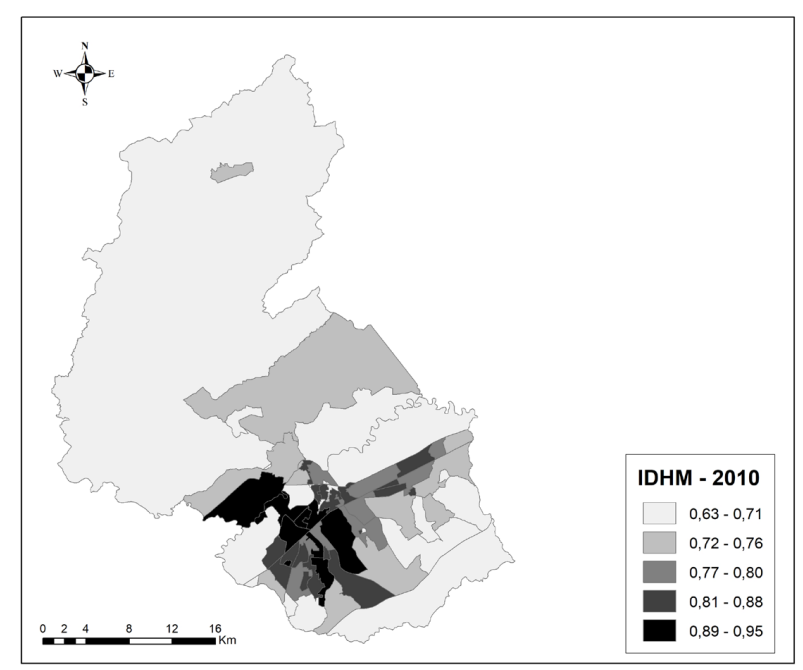

Figura 5 - IDHM do município de São José dos Campos, segundo as Unidades de Desenvolvimento Humano (UDH), em 2010

Fonte: PNUD (2013). Elaborado por Daniel José de Andrade.

A respeito dos "tempos rápidos e lentos", Santos (2012) trata de uma contabilidade relativa do tempo vivenciado pelos "homens, empresas e instituições", que se diferencia de lugar a lugar. Aplicando tal conceito ao caso em estudo, quando a cidade se destacava por sua função senatorial, o tempo social vivenciado e o ritmo da vida urbana eram predominantemente mais "lentos", criando um ambiente cujas condições necessárias ao tratamento de doenças pulmonares propiciavam a melhora do paciente. Hoje, ao contrário, na cidade de São José dos Campos os tempos sociais são regidos pela velocidade e instantaneidade das ordens, das informações, das práticas, do acontecer cotidiano, que condicionam a sociedade não mais ao consumo dos 
benefícios para a cura da temível moléstia do peito, mas ao consumo pelo consumo e, inclusive, ao consumo de ideologias e outras formas de representação social.

Análise de representações sociais e da identidade do município de São José dos Campos

Na busca de compreensão de representações sociais e da identidade do município de São José dos Campos constatou-se, a partir da segunda metade do século XX, um processo de industrialização e urbanização com raízes no planejamento, pelo Estado, da formulação de um locus industrial-tecnológico.

Qual imagem de cidade o poder público tenta promover para São José dos Campos? Para tentar responder a pergunta, recorremos a consulta ao endereço eletrônico da Prefeitura de São José dos Campos.

0 símbolo em questão é uma adaptação da bandeira de São José dos Campos (a), elaborada pela Lei n. 655, de 1960, cuja "[...] roda dentada em ouro simboliza a riqueza sempre ascendente do Município" (São José dos Campos, 1960). Dentre os elementos oficiais, a figura da roda dentada foi adotada como elemento oficial do poder público (b). Considerando o contexto histórico do município na década de 1960, essa riqueza estaria centrada na capacidade produtiva industrial em curva ascendente, após a fase sanatorial (Figura 6).

É possível traduzir tal simbologia como uma representação social do locus urbano-industrial. Se considerarmos que uma roda dentada é um componente de uma engrenagem essencial para o pleno funcionamento de uma máquina, então São José dos Campos está para as máquinas assim como a indústria e a tecnologia estão para São José dos Campos.

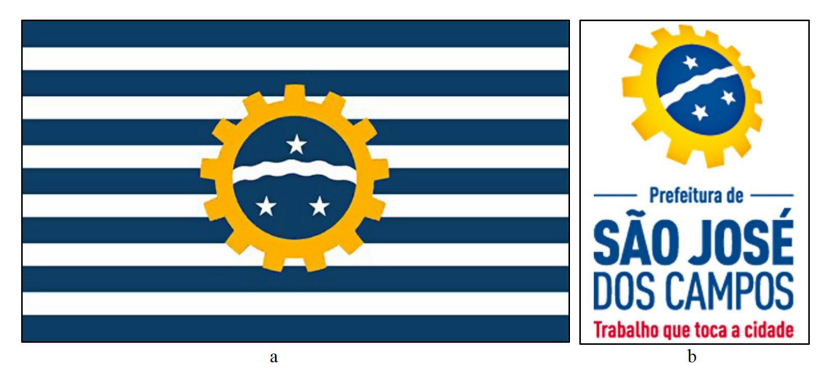

Figura 6 - Bandeira do município de São José dos Campos (a) e símbolo veiculado pela prefeitura de São José dos Campos (b) Fonte: PMSJC (São José dos Campos, 2015).
Resumindo, pode-se constatar que a imposição simbólica dos elementos contidos na lei de 1960 atingiu o efeito desejado pelos idealizadores dos conceitos prescritos nos símbolos oficiais de São José dos Campos. Logicamente, tal simbologia se apresenta em consonância com a futura realidade do município que, no ano de 2013, e de acordo com o SEADE (2013), possuía um dos maiores valores em Produto Interno Bruto do Estado de São Paulo e do Brasil: a incrível cifra de R\$27.401,017 bilhões de reais.

\section{Arapeí, "um pequeno caminho para o céu!"}

O município de Arapeí foi instituído recentemente, por meio de lei estadual n. 7.664, de 31 de dezembro de 1991 (São Paulo, 1991). Parte da história de Arapeí se deu como distrito (a) do município de Bananal (b) (Figura 7). As raízes, memórias e identidade do município, até a data de criação, estão vinculadas ao café e com a condição histórica descrita por Monteiro Lobato (1969) como Cidades Mortas do Vale do Paraíba Paulista.

A respeito de Bananal, os relatos escritos por Müller (1969, p. 25) esclarecem que sua formação

[...] deriva de desbravamento feito por fluminenses e de patrimônio instituído em 1783 por João Barbosa de Camargo e sua mulher, D. Maria Ribeiro de Jesus, com capela, que tinha por orago o Senhor Bom Jesus do Livramento do Bananal.

Se o café foi o precursor do desenvolvimento das cidades valeparaibanas no século XIX, seu abandono trouxe impactos negativos para a Região do Vale do Paraíba, principalmente para os municípios produtores de café. De acordo com Müller (1969, p. 29-30), a expansão da cultura do café na região não foi homogênea. Em alguns municípios, como Areias, Bananal, Santa Isabel, sua adoção foi rápida. Em outros, como Guaratinguetá, Taubaté, Lorena e São José dos Campos, seu avanço foi mais lento e gradativo. Para Müller (1969, p. 118), no século XX,

as cidades de Areias, São José do Barreiro e Bananal empobrecidas pela decadência do café e marginalizadas pelo deslocamento do eixo de circulação pelo traçado da E. F. Central do Brasil, passando por Cruzeiro, 'bruxoleavam' nas primeiras décadas do século. São as 'cidades 
mortas' de Monteiro Lobato, onde 'tudo foi e nada é'.

Para contextualizar a importância da produção de café no Vale do Paraíba, a Tabela 3 mostra um panorama da produção entre os anos de 1854 até 1935, e a queda no decorrer desse período. É válido ressaltar que o município de Bananal alcançou a condição de maior produtor em 1854; em 1886, a produção de Bananal foi somada à do município de Areias (Milliet, 1946, apud Ricci, 2006).

Conforme afirma Müller (1969, p. 118),
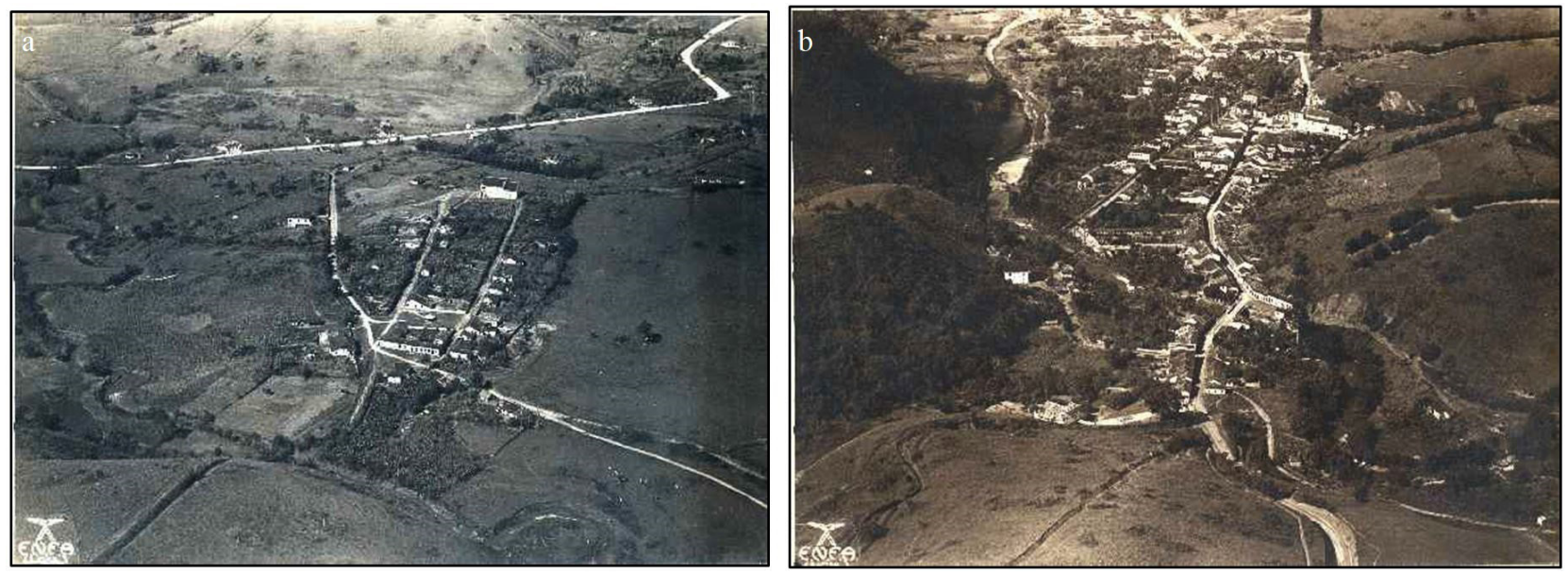

[...] um pouco de alento chegara até estes centros com a abertura ao tráfego, em 1924, da primeira estrada de rodagem Rio-São Paulo, que por elas [cidades históricas do Vale do Paraíba] passava, mas, em 1950, inaugurada a Rodovia Presidente Dutra, novamente caem no marasmo.

Müller conclui que, "[...] de fato, pouco chegou a influir a velha estrada de rodagem no crescimento dessas cidades".

De acordo com Müller (1969), entre os anos de 1934 a 1960, o município de Bananal apresentou

Figura 7 - Distrito de Arapeí (a) e núcleo urbano de Bananal (b), 1939/1940 Fonte: IGC (2015).

Tabela 3 - Produção de café, arrobas e porcentagem, no Vale do Paraiba

\begin{tabular}{|c|c|c|c|c|c|c|c|c|}
\hline \multirow{2}{*}{ Municípios } & \multicolumn{2}{|c|}{1854} & \multicolumn{2}{|c|}{1886} & \multicolumn{2}{|c|}{1920} & \multicolumn{2}{|c|}{1935} \\
\hline & Arrobas & $\%$ & Arrobas & $\%$ & Arrobas & $\%$ & Arrobas & $\%$ \\
\hline Areias & 386.094 & 13,9 & 480.000 & 24,6 & 79.900 & 10,8 & 52.335 & 5,9 \\
\hline Bananal & 554.600 & 20,0 & * & * & 15.847 & 2,2 & 13.650 & 1,6 \\
\hline Guaratinguetá & 100.885 & 3,6 & 350.000 & 17,9 & 97.687 & 13,3 & 63.625 & 7,2 \\
\hline Jacareí & 240.010 & 8,7 & 86.000 & 4,4 & 21.880 & 3,0 & 39.540 & 4,5 \\
\hline Lorena & 125.000 & 4,5 & 176.667 & 9,0 & 130.961 & 17,8 & 107.040 & 12,2 \\
\hline Paraibuna & 118.320 & 4,3 & 10.000 & 0,5 & 11.747 & 1,6 & 68.725 & 7,8 \\
\hline Pindamonhangaba & 350.000 & 12,6 & 200.000 & 10,2 & 84.520 & 11,5 & 51.109 & 5,8 \\
\hline São José dos Campos & 60.000 & 2,2 & 250.000 & 12,8 & 51.173 & 6,9 & 134.254 & 15,3 \\
\hline Taubaté & 354.730 & 12,8 & 360.000 & 18,4 & 222.147 & 30,2 & 324.293 & 36,8 \\
\hline Outros municípios & 484.000 & 17,4 & 41.600 & 2,1 & 20.833 & 2,8 & 25.246 & 2,9 \\
\hline Total da regic̃o & 2.773 .639 & 100,0 & 1.954 .267 & 100,0 & 736.695 & 100,0 & 880.167 & 100,0 \\
\hline
\end{tabular}

Fonte: Milliet (1946, apud Ricci, 2006, p. 26); * sem dados registrados para 0 período. 
uma população majoritariamente rural, ao contrário do que ocorreu em São José dos Campos que, a partir de 1940, apresentava uma inversão nos indicadores demográficos, com a população urbana superando a rural (Tabela 4).

Os primeiros indícios de Arapeí têm origem em 15 de maio de 1891, porém somente em 30 de dezembro de 1991 Arapeí se tornou município autônomo.

Na década de 1950, o distrito de Arapeí contava com apenas um estabelecimento industrial voltado à produção têxtil. Segundo Müller (1969, p. 153), nessa condição de cidade monoindustrial encontravam-se "Redenção da Serra, com sua pequena indústria quase artesanal, de esteiras de palha e Arapeí, com seu modesto estabelecimento têxtil de 50 operários".

Na década de 1950, a inauguração da Rodovia Presidente Dutra condicionou a estagnação socioespacial dos municípios que tinham na antiga Estrada Rio-São Paulo sua principal via de circulação. Desde então, “[...] o segmento turístico passou a ser o principal foco de Arapeí, graças às suas riquezas naturais, ao artesanato e ao seu diversificado patrimônio cultural" (Arapeí, 2015).

A emancipação de Arapeí ocorreu em 1991, com a promulgação da lei estadual n. 7.664, de 31 de dezembro de 1991, instituindo-o como município. Em 1995, Arapeí possuía um total de 2.238 pessoas residindo no município (IBGE, 2010). No censo oficial do ano de 2000, a contagem da população considerou a condição urbana e a rural. No curto período de existência, Arapeí sempre apresentou um percentual de população rural superior à população urbana. Em 2010, o número de pessoas que residiam em Arapeí apresentou uma ligeira queda nos valores absolutos, assim o percentual de pessoas residindo em áreas rurais foi de 72,54\% em 2000 para 75,21\%, já a variação negativa da população urbana foi de $27,46 \%$, em 2000, para 24,79\%, em 2010, não alterando o perfil demográfico do município (Tabela 5).

Após sua emancipação como município, Arapeí buscou as bases de seu desenvolvimento. Segundo a Prefeitura Municipal de Arapeí (2015) “[...] a infraestrutura como município, iniciada praticamente do zero, vai sendo conquistada a passos largos rumo a um desenvolvimento sustentável que implique em melhor qualidade de vida a seus cidadãos". A igreja de Santo Antônio (a) e o núcleo urbano (b) expressam a realidade contemporânea deste município (Figura 8).

Devido ao seu contexto histórico, o município de Arapeí firmou-se no turismo. Com os aspectos de uma pequena cidade do interior, foi inserida no circuito turístico do Vale Histórico e dos Caminhos da Corte. A representação social do município aparece no endereço eletrônico da Prefeitura de Arapeí conforme Figura 9.

A frase "Um pequeno caminho para o céu!" sugere aquilo que a cidade tem de mais positivo, ou seja, a tranquilidade de uma cidade pequena, que deixou de ser privilégio dos grandes centros urbanos. Outra informação, que nos dá indícios da identidade cultural

Tabela 4 - População urbana e rural em Bananal entre 1934 e 1960

\begin{tabular}{ccccccc}
\hline Ano & Total & $\%$ & Urbana & $\%$ & Rural & $\%$ \\
\hline 1934 & 12.932 & 100 & 1.377 & 10,65 & 11.555 & 89,35 \\
1940 & 11.566 & 100 & 1.641 & 14,19 & 9.925 & 85,81 \\
1950 & 11.190 & 100 & 2.058 & 18,39 & 9.132 & 81,61 \\
1960 & 9.859 & 100 & 2.189 & 22,20 & 7.670 & 77,80 \\
\hline
\end{tabular}

Fonte: Müller (1969).

Tabela 5 - Dados demográficos de Arapeí - 2000 e 2010

\begin{tabular}{ccccccc}
\hline Ano & Total & $\%$ & Urbana & $\%$ & Rural & $\%$ \\
\hline 2000 & 2.618 & 100 & 719 & 27,46 & 1.899 & 72,54 \\
2010 & 2.493 & 100 & 618 & 24,79 & 1.875 & 75,21 \\
\hline
\end{tabular}

Fonte: IBGE (2010). 

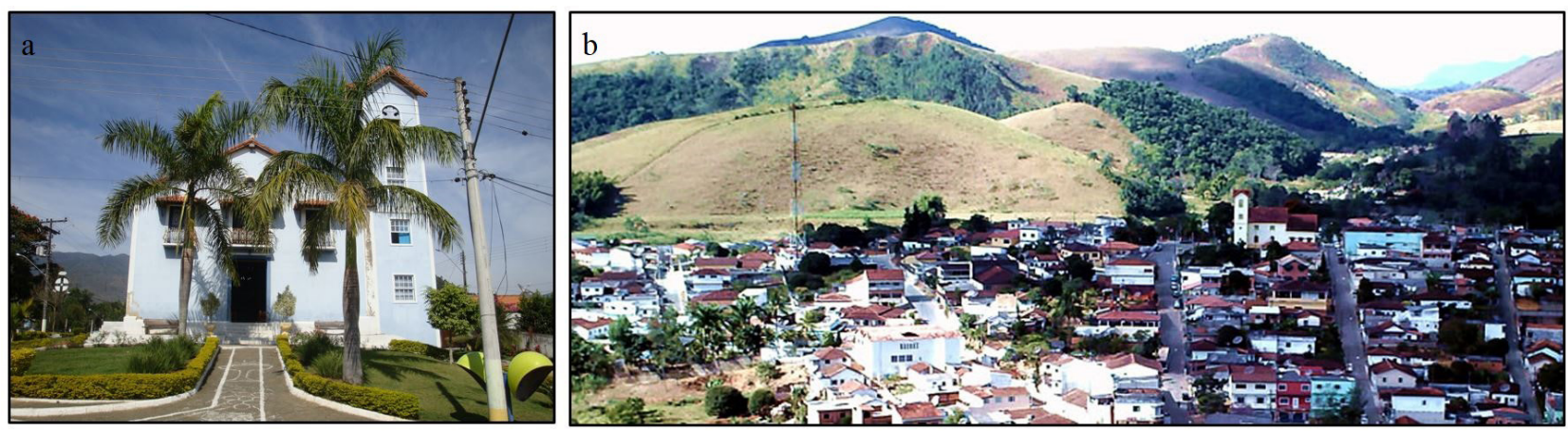

Figura 8 - Igreja Santo Antônio (a) e núcleo urbano de Arapeí (b) ${ }^{\star \star}$ Fonte: Acervo pessoal (2009)*; Prefeitura Municipal de Arapeí (2015)**.

do município, consiste no poder da religiosidade. Segundo dados obtidos na página eletrônica da prefeitura de Arapeí (2015), das 2.493 pessoas recenseadas em 2010, 89,25\% participavam de alguma denominação religiosa; desses, 1.742 ou $69,88 \%$ se disseram católicos apostólicos romanos, 469 pessoas ou $18,81 \%$ das pessoas se disseram evangélicas e 14 ou $0,56 \%$, espíritas.

Quanto à qualidade de vida do arapeiense, dados obtidos no PNUD para o Desenvolvimento Humano revelam que, em 2010, o IDH para todo o município foi de 0,68 , índice médio para todo o território. Segundo esses dados de 2010, em Arapeí, tanto a população do núcleo urbano quanto a população rural apresentam as mesmas condições de vida (Figura 10).

A paisagem bucólica de Arapeí, fruto em boa parte de um marginalismo geográfico e econômico na Região do Vale do Paraíba, apresenta características de um urbano misturado ao rural. Segundo Santos (1996), referencialmente ao meio geográfico, Arapeí enquadra-se como uma zona opaca, local com baixa densidade de características técnicas, científicas e informacionais. Pautando-se nesses conceitos, vemos em Arapeí características de um período histórico há muito superado por São José dos Campos e outros municípios da região que participaram do projeto nacional desenvolvimentista. A instantaneidade parece não ser a regra nesse ambiente de predomínio de modos e maneiras típicas do mundo rural. Em Arapeí, o tempo é outro, o ritmo não obedece aos modelos produtivos quando comparada com outras municipalidades da RMVPLN. Devido a esse tempo mais lento e às características da população de Arapeí, a conservação de valores pautados na cultura e tradição se faz mais presente.

\section{Prefejutral Munjajpal cle Arajpej} Un pequeno carnicho parn o cét

Figura 9 - veiculado pela prefeitura de Arapeí Fonte: Prefeitura Municipal de Arapeí (2015).

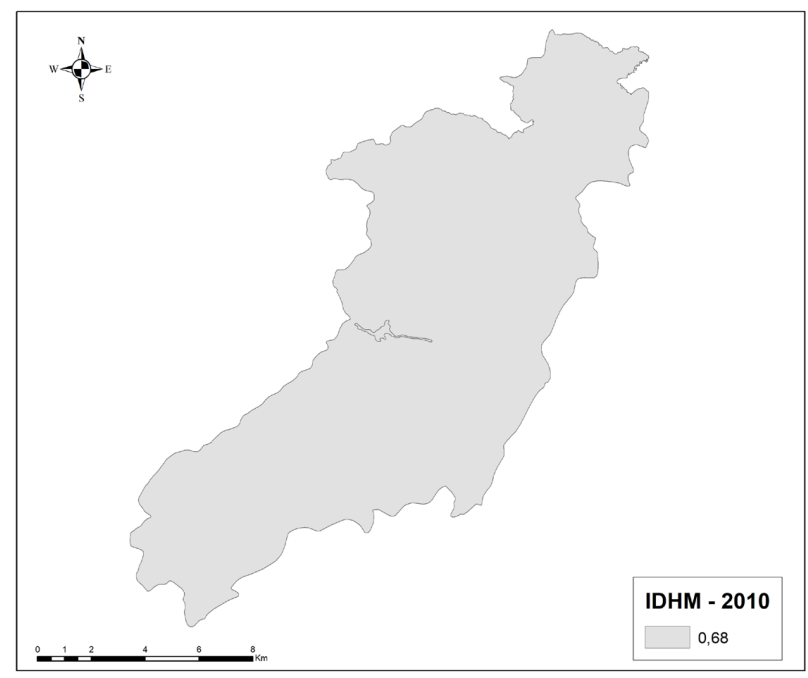

Figura 10 - IDH do município de Arapeí em 2010

Fonte: Adaptado de PNUD (2013). Elaborado por Daniel José de Andrade.

As imagens da cidade projetadas pela municipalidade são criações simbólicas carregadas de conteúdo em que predomina o discurso dos que querem perpetuar as narrativas. Decifradas, tais representações do real revelam sentidos, formas de ver e entender a realidade de Arapeí que são particulares dos agentes que as criaram e que por isso se consolidam em detrimento de outras representações (de outros agentes). De fato, o passado áureo de Arapeí foi ressignificado de forma a 
preservá-lo na memória e, ao mesmo tempo, na procura de se dar sentido a uma nova realidade do município.

\section{Correlações entre aportes teóricos e a análise das representações sociais em São José dos Campos e Arapeí}

As representações simbólicas veiculadas na forma de ideias e imagens de São José dos Campos e Arapeí possibilitam estabelecer correlações com os aportes teóricos selecionados sobre as representações sociais, possibilitando avaliar o alcance e os limites da abordagem no campo do planejamento urbano e regional.

Ao mesmo tempo em que tais ideias e imagens se ancoram nos processos históricos e no tecido sociocultural e político dos municípios, representando-os, constituem versões da realidade concebida e comunicada por agentes do poder público municipal, que se inserem e se posicionam na realidade local de modo distinto de outros agentes ou segmentos sociais.

Se as representações sociais das cidades também participam da estruturação do espaço urbano (Cruz \& Arruda, 2008), elas podem ter um peso preponderante na forma de planejar e produzir o espaço social e urbano.

Assim sendo, considerando apenas as representações oficiais e, por isso, deixando de lado diversas outras representações sociais (criadas por diferentes segmentos sociais), pode-se incorrer em versões parciais ou simplificadas da realidade socioespacial dos municípios que, combinadas a posturas deterministas e descomprometidas com os interesses da sociedade no seu todo, terminam por se revelar distorcidas, culminando na produção de espaços de modo igualmente distorcido, porque socialmente exclusivista.

Nesse sentido, pode-se conjecturar, para o caso de São José dos Campos, por exemplo, a prevalência de desejos e interesses de pequenos grupos que, afinados às orientações desenvolvimentistas do período da industrialização e internacionalização do capital no país, projetam sobre o corpo social do município as suas representações ou simbologias do desenvolvimento industrial e tecnológico da cidade, assumindo, com força política, a função de idealizadores do que supostamente viria a ser o espaço de vida de interesse comum.

A cidade se reurbaniza em novas dimensões, as paisagens se estendem e se povoam de grandes vias, estabelecimentos industriais e de pesquisa científica e tecnológica, sob a imposição e legitimação (mais ou menos consciente) de imagens e discursos desfocados das realidades desiguais produzidas pelo mesmo processo de condução política.

O município de São José dos Campos, com sua imagem e concretude de moderno complexo tecnológico-industrial-aeroespacial remodela-se enquanto espaço potencial e arena de reconstrução de ideário e mundo hegemônicos (inspirados no sistema ideológico do mundo global), contrapondo-se, por suas duras fronteiras, à magnitude real da heterogeneidade social e do espaço urbano em sua totalidade.

No caso de Arapeí, sua situação regional defasada em relação aos ritmos do projeto desenvolvimentista e da globalização econômica de nossos dias - imposta territorialmente, inclusive, pelo eixo rodoviário da Dutra, que torna marginais os antigos caminhos terrestres do conhecido Vale Histórico - concorre não somente para uma relativa ausência de dinamismos sociais e fluxos econômicos, mas também para uma provável idealização de horizontes e estilos de vida enquadrada no tradicionalismo e em ritmos sociais pacatos. As imagens oficiais de Arapeí denotam essa atmosfera social criadora e recriadora de práticas socioespaciais tradicionais. Os novos alentos trazidos com a perspectiva de sua inserção no circuito do turismo histórico do Vale do Paraíba reforçam ainda mais as representações sociais valorativas do patrimônio cultural por meio do apego ao simbolismo do passado áureo do café.

Ao ideário das mudanças engrenadas às ordens neoliberais de São José dos Campos contrapõe-se, no contexto regional valeparaibano, a mesma ausência de políticas públicas para pequenas cidades também em Arapeí, que se reveste de sinais dos novos tempos pela frágil economia do turismo e a exploração simbólica de sua dimensão histórica e cultural.

Como reverter essa falta de equidade socioespacial, regional e local no atual momento de discussões sobre o futuro da recém-instituída Região Metropolitana do Vale do Paraíba e Litoral Norte?

Supostamente, toda ordem de mudanças nasce da dinâmica relacional entre a sociedade e seu espaço de vida em comum (Jovchelovitch, 1994), tendo no fluxo recriador das representações sociais (dessa vida social e do lugar que a abriga), com seu caráter mediador de atividade simbólica (Jovchelovitch, 1994), o espaço potencial para o reconhecimento e a elaboração mental de sujeitos sociais os 
mais diversos. E é justamente nesse domínio de significação e construção coletiva de novos saberes, pelo resgate da consciência dos sujeitos sociais, que a prevalência do ser social (Jodelet, 2002) poderá, de fato, reconstruir a dimensão pública e social do espaço urbano e do território municipal e o futuro poderá ser engendrado na perspectiva dos direitos e deveres de cidadania.

Reiterando-se a importância da força de resistência e da participação dos diversos segmentos sociais na criação de diversas representações (Jovchelovitch, 1994) do espaço urbano e, por conseguinte, na busca de reconstrução coletiva do espaço de todos, os estudos sobre representações sociais podem colaborar na construção de novas abordagens para o planejamento urbano e regional, como forma de posicionamento e compromisso diante das forças ou movimentos político-ideológicos de imposição de modelos de desenvolvimento e vida social e urbana alheios às demandas sociais locais.

Nesse sentido, por exemplo, as contribuições metodológicas de Arruda (2014), sobre o uso de mapas mentais, poderiam elucidar um futuro prognóstico da identidade social, tanto de São José dos Campos quanto de Arapeí. Diferentemente da veiculação ideologizada das representações simbólicas oficiais, os mapas mentais auxiliariam qualitativamente, trazendo amostras diversificadas do que pensam os diferentes cidadãos, as suas representações dos espaços de interesse e uso comuns, sua visão sobre o espaço construído e o futuro social.

\section{Considerações finais}

Este estudo apresentou uma leitura das paisagens construídas pelo olhar da história da formação das municipalidades e por meio de simbologias ou representações sociais sobre elas.

Utilizando os conceitos sobre representações sociais, entende-se que a metamorfose do espaço urbano, materializada em suas paisagens, consolidou em São José dos Campos a identidade de cidade tecnológica, construída por segmentos sociais hegemônicos, incluindo o poder público que, no geral, tende a favorecer a força do grande capital.

Nesse sentido, percebe-se por trás das representações sociais o projeto nacional desenvolvimentista cuja implementação, a partir da metade do século passado, e retomada nas últimas décadas, com as marcas neoliberais, tem norteado o planejamento local do município a cumprir o seu papel e a relegar ao passado a antiga representação social de "cidade dos doentes", que se torna anacrônica diante das novas determinações. Foi preciso uma nova simbologia para o município, a da engrenagem, que achou, na indústria e na tecnologia, a base constitutiva e a identificação de lugar.

Arapeí, por sua vez, apresentou situação inversa a de São José dos Campos. A paisagem construída no passado, em condições atuais, envolveu o município em uma situação de marginalidade histórica que não permitiu sua participação no desenvolvimento experimentado pelos vizinhos prósperos da região, sobretudo daqueles localizados ao redor do eixo Dutra. Com o fim da fase áurea do café, Arapeí começou a atrair outros contingentes que chegavam, e ainda chegam, para apreciar a vida pacata de cidade do interior, que não se encontra em ambiente urbano-global. Se Arapeí apresenta um retrato do tempo esquecido - sem os labirintos de luzes, os outdoors ou arranha-céus, cenários tão presentes na paisagem construída de São José dos Campos - a municipalidade em questão expõe a incerteza da condição pós-moderna, podendo até especular que, nas próximas décadas, as marcas do progresso emerjam em Arapeí, talvez pela via da intensificação do turismo.

Foi perceptível também que esses dois meios geográficos constituídos nos territórios municipais, apesar de heterogêneos quanto a paisagens construídas, apresentam uma representação simbólica similar: o céu! Se para o município de São José dos Campos, sua base produtiva é alicerçada no aparato científicotecnológico do setor aeroespacial, e esse cria uma representação social para o município; em Arapeí, o céu de ar puro da Mata Atlântica e da religiosidade representa o espaço diferenciado, formado pela identidade e cultura do arapeiense. Tal espaço, promovido como ponto turístico, onde abundam realidades escassas em condições de alta complexidade urbanizada, mesmo assim não deixa de ser produto a ser consumido, tal como nas grandes cidades, tal qual em São José dos Campos.

Em síntese, o estudo realizado, com as devidas correlações teórico-empíricas explicitadas, possibilitou avaliar, para além das representações de apenas um segmento social, o interesse e a pertinência da aplicação de teorias e metodologias de análise das representações 
sociais em estudos que possam subsidiar processos de planejamento urbano e regional conduzidos com participação social mais ampla.

\section{Referências}

Andrade, D. J. (2015). Desenvolvimento regional e o meio técnico-científico-informacional: uma análise dos contrastes socioeconômicos e espaciais da Região Metropolitana do Vale do Paraíba e Litoral Norte (Dissertação de mestrado). Universidade do Vale do Paraíba, São José dos Campos.

Arapeí. Prefeitura Municipal - PMArapeí. (2015). Material Institucional. Recuperado em 11 dezembro de 2015, de http://arapei.tempsite.ws

Arruda, A. (2002). Teoria das representações sociais e teoria de gênero. Cadernos de Pesquisa, 117(117), 127-147. http://dx.doi.org/10.1590/S0100-15742002000300007.

Arruda, A. (2014). Social imaginary and social representations of Brazil. Papers on Social Representations, 23, 1-23. Recuperado em 11 dezembro de 2015, de http://www. psych.lse.ac.uk/psr/

Becker, B. K., \& Egler, C. A. G. (2003). Brasil: uma nova potência regional na economia-mundo (4. ed). Rio de Janeiro: Bertrand Brasil.

Cruz, A. C. D., \& Arruda, A. (2008). Por um estudo do ausente: a ausência como objetivação da alteridade em mapas mentais no Brasil. Estudos e Pesquisas em Psicologia, 3, 789-806. Recuperado em 11 dezembro de 2015, de http://www.revispsi.uerj.br/v8n3/artigos/pdf/v8n3a16.pdf

Força Aérea Brasileira - FAB. (2012). Marcas do trabalho de Niemeyer podem ser encontradas em edifícios e monumentos da FAB. Brasília. Sessão Memória. Recuperado em 11 dezembro de 2015, de http://www.fab.mil.br/noticias/ mostra/13697

Freitag, B. (2012). Teorias da cidade. Campinas: Papirus.

Fundação Sistema Estadual de Análise de Dados - SEADE. (2013). Informações de municípios paulistas. São Paulo: SEADE. Recuperado em 17 dezembro de 2015, de http:// www.imp.seade.gov.br/frontend/\#/

Instituto Brasileiro de Geografia e Estatística - IBGE. (2010). Dados dos censos demográficos de 2000 e 2010. Rio de Janeiro: IBGE. Recuperado em 5 dezembro de 2015, de http://www.ibge.gov.br
Instituto de Geografia e Cartografia - IGC. (2015). Aerofotos oblíquas em 1939/1940. São Paulo: IGC. Recuperado em 10 dezembro de 2015, de http://www.igc.sp.gov.br/ produtos/galeria_aerofotos.aspx

Jodelet, D. (2001). Representações sociais: um domínio em expansão. In D. Jodelet (Ed.), As representações sociais (pp. 17-44). Rio de Janeiro: EDUERJ.

Jodelet, D. (2002). Cidade e a memória. In V. Del Rio, P. Rheingantz, \& C. Duarte (Eds.), Projeto do lugar: colaboração entre psicologia, arquitetura e urbanismo, Rio de Janeiro: Contra Capa.

Jovchelovitch, S. (1994). Vivendo a vida com os outros: intersubjetividade, espaço público e representações sociais. In S. Jovchelovitch, \& P. Guareschi, (Eds.), Textos em representações sociais (pp. 63-85). Petrópolis: Vozes.

Lobato, M. (1969). Cidades mortas. São Paulo: Brasiliense.

Milgram, S., \& Jodelet, D. (1976). Psychological maps of Paris. In J. Sabini, \& M. Silver (Eds.), The individual in a social world: essays and experiments (pp. 88-113). New York: McGraw-Hill.

Müller, N. L. (1969). O fato urbano da Bacia do Rio Paraíba: Estado de São Paulo. Rio de Janeiro: Divisão Cultural, Fundação IBGE.

Programa das Nações Unidas para o Desenvolvimento - PNUD. Índice de Desenvolvimento Humano Municipal Brasileiro - IPEA. (2013). Atlas do Desenvolvimento Humano no Brasil. Brasília: PNUD, FJP.

Ricci, F. (2006). A economia cafeeira e as bases do desenvolvimento no Vale do Paraíba Paulista. Revista de História Econômica \& Economia Regional Aplicada, 1(1), 21-34. Recuperado em 10 dezembro de 2015, de http:// www.ufjf.br/heera/files/2009/11/artigo02.pdf

Rosemberg, J. (1999). Tuberculose: aspectos históricos, realidades, seu romantismo e transculturação. Boletim de Pneumologia Sanitária, 7(2), 5-29. Recuperado em 10 dezembro de 2015, de http://scielo.iec.pa.gov.br/scielo. php?pid=S010360X1999000200002\&script=sci_abstract Santos, M. (1996). Técnica, espaço, tempo: globalização e meio técnico-científico-informacional (2. ed.) São Paulo: Hucitec.

Santos, M. (2012). Natureza do espaço: técnica e tempo, razão e emoção (4. ed.). São Paulo: EDUSP. 377 p. 
São José dos Campos. (1960, 2 de fevereiro). Lei no 655, de 2 de fevereiro de 1960. Institui a bandeira do município de São José dos Campos. São José dos Campos: DSJC, n. 1.064.

São José dos Campos. Prefeitura Municipal - PMSJC. (2015). Material Institucional. Recuperado em 11 dezembro de 2015, de http://www.sjc.sp.gov.br

São Paulo (1991, 30 de dezembro). Lei no 7.664, de 30 de dezembro de 1991. Dispõe sobre alterações no Quadro Territorial-Administrativo do Estado. São Paulo: Diário Oficial do Estado de São Paulo, artigo 2.

Sêga, A. R. (2000). O conceito de representação social nas obras de Denise Jodelet e Serge Moscovici. Revista Anos, 90(13), 128-133. Recuperado em 10 dezembro de 2015, de http://www.ufrgs.br/ppghist/anos90/13/13art8.pdf

Souza, A. A. M. (2008). A especialização do lugar: São José dos Campos como Centro da Tecnologia Aeroespacial no
País (Tese de doutorado). Faculdade de Filosofia, Ciências Humanas e Letras, Universidade de São Paulo, São Paulo.

Souza, A. A. M., \& Costa, W. M. (2010). Atividades industriais no interior do estado de São Paulo: uma análise da formação do complexo tecnológico-industrial-aeroespacial de São José dos Campos. In S. F. Costa, \& L. F. Mello (Eds.), Crescimento urbano e industrialização em São José dos Campos. (1. ed., pp. 87-108). São José dos Campos: Intergraf.

Vianna, P. V. C. (2010). A estância climatérica de São José dos Campos: condição natural ou construção social? Um resgate pela memória. In V. Zanetti (Ed.), Fase sanatorial de São José dos Campos: espaço e doença (1. ed., pp. 5172). São José dos Campos: Univap.

Recebido: Jun. 29, 2016

Aprovado: Jan. 13, 2017 